\title{
Five Novel Locations of Neocentromeres in Human: 18q22.1, Xq27.1 27.2, Acro p13, Acro p12, and Heterochromatin of Unknown Origin
}

\author{
E. Klein ${ }^{a} \quad$ M. Rocchi ${ }^{b} \quad$ A. Ovens-Raeder ${ }^{c} \quad$ N. Kosyakova ${ }^{a} \quad$ A. Weise ${ }^{a}$ \\ M. Ziegler ${ }^{a}$ M. Meins ${ }^{d}$ S. Morlot ${ }^{d}$ W. Fischer ${ }^{d}$ M. Volleth ${ }^{e}$ A. Polityko ${ }^{f}$ \\ C. Mackie Ogilvieg C. Kraus ${ }^{\mathrm{h}} \quad$ T. Liehr ${ }^{\mathrm{a}}$ \\ ${ }^{a}$ Institute of Human Genetics, Jena University Hospital, Friedrich Schiller University, Jena, Germany; ${ }^{\text {b Department }}$ \\ of Biology, University of Bari, Bari, Italy; ${ }^{C}$ Praxis für Humangenetik, München, ${ }^{d}$ Partnerschaft, Hannover, ${ }^{e}$ Institute \\ of Human Genetics, University Hospital, Magdeburg, Germany; ${ }^{f}$ Institute of Hereditary Diseases, Minsk, Belarus;

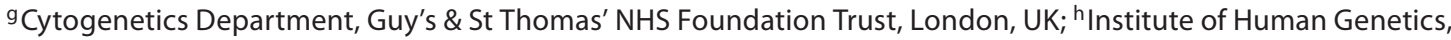 \\ Erlangen, Germany
}

\section{Key Words}

18q22.1 • Acro p12 - Acro p13 • Centromere repositioning •

Neocentromere $\cdot$ Small supernumerary marker

chromosomes $(\mathrm{sSMC}) \cdot \mathrm{Xq} 27.1 \sim 27.2$

\begin{abstract}
Since the first report in 1993, an ectopic centromere, i.e. neocentromere formation, has been reported in more than 100 small supernumerary marker chromosomes (sSMC), in 7 instances of centromere repositioning, and in about a dozen cases with more complex chromosomal rearrangements. Here we report 2 new cases with centromere repositioning and 3 neocentric SSMC consisting exclusively of heterochromatic material. Yet, no centromere formation was reported for the regions 18q22.1 and Xq27.1 27.2 as it was observed in the 2 cases with centromere repositioning here; in both cases, cytogenetically an inversion was suggested. Two of the 3 neocentric sSMC were derived from a short arm of an acrocentric chromosome. The remainder neocentric sSMC case was previously reported and was stainable only by material derived from itself.

Copyright $\odot 2012$ S. Karger AG, Basel
\end{abstract}

Human neocentromeres have been known since 1993 [Voullaire et al., 1993]. Since then, 107 neocentric small supernumerary marker chromosomes (sSMC) [Liehr 2011], 7 carriers of centromere repositioning, and 13 cases with other rearrangements including neocentromere formation have been reported [reviewed in Liehr et al., 2010]. Here we describe 2 more cases with centromere repositioning and 3 neocentric sSMC, the latter exclusively derived from heterochromatic material.

\section{Two New Cases with Centromere Repositioning}

Case 1

Amniocentesis was done due to advanced maternal age; sonography was normal. A derivative chromosome 18 was detected in GTG banding and suspected to comprise a pericentric inversion. Fluorescence in situ hybridization (FISH) analysis using the corresponding centromere-specific probe revealed that the primary constriction was not in concordance with the alphoid DNA on the derivative chromosome (results not shown). By array-

\section{KARGER}

Fax +4161306 1234

E-Mail karger@karger.ch

www.karger.com
(C) 2012 S. Karger AG, Basel

$1424-8581 / 12 / 1363-0163 \$ 38.00 / 0$

Accessible online at:

www.karger.com/cgr
Dr. Thomas Liehr

Universitätsklinik Jena, FSU

Institut für Humangenetik

Postfach, DE-07740 Jena (Germany)

Tel. +493641935 533, E-Mail i8lith@mti.uni-jena.de 


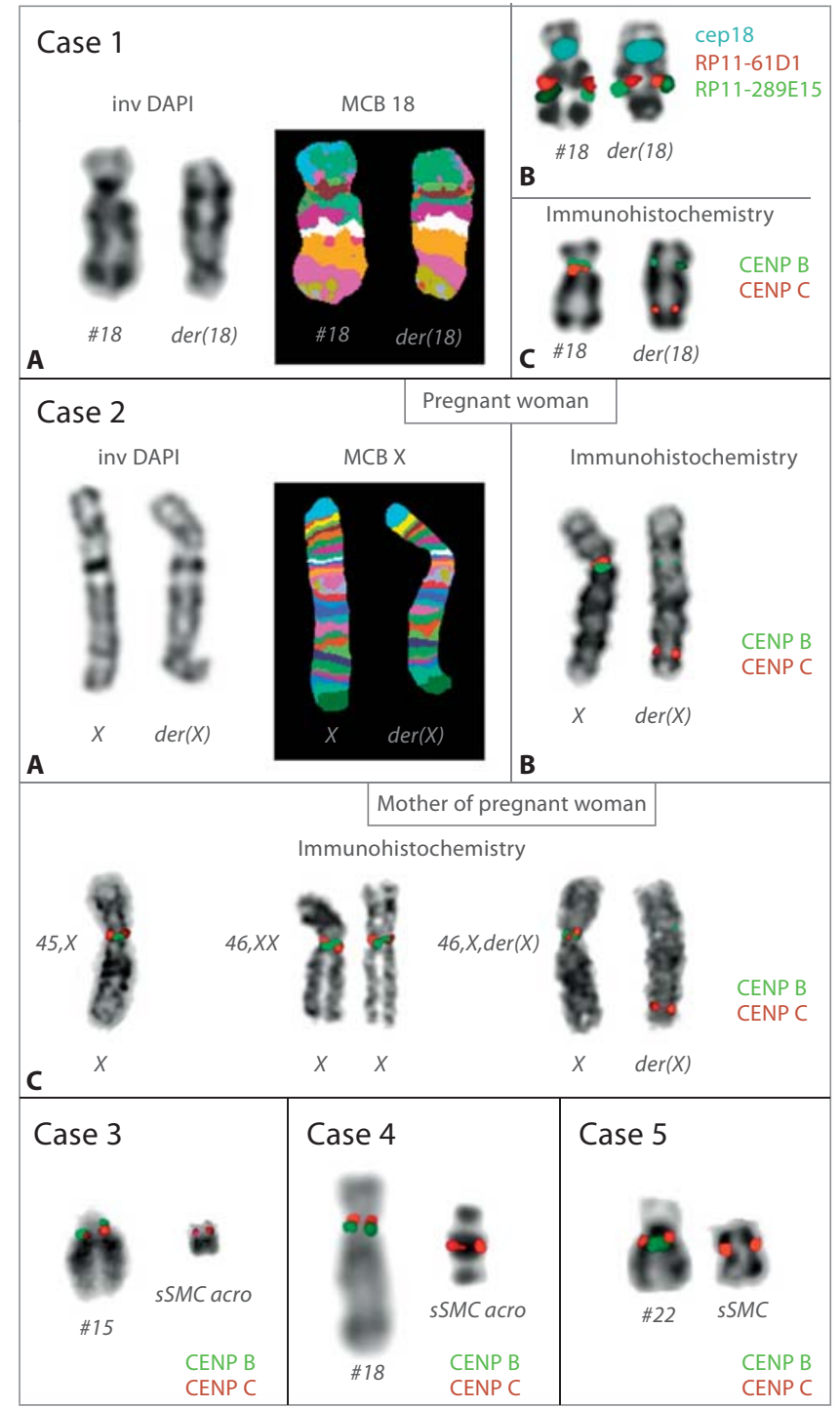

Fig. 1. Summary of the neocentric chromosomes of the 5 reported cases. Case 1 Array-proven multicolor banding (aMCB) revealed that the derivative chromosome $18(\operatorname{der}(18))$ did not harbor an inversion, but possibly a neocentromere (A). FISH using BACs flanking an ancestral centromere revealed there is no co-localization of both (B). Immunohistochemistry with CENP-specific antibodies confirmed the neocentromere to be present at $18 \mathrm{q} 22.1$ (C). Case 2 The pregnant woman had the identical derivative $\mathrm{X}$ chromosome as the fetus (latter not shown). MCB (A) and immunohistochemistry $(\mathbf{B})$ proved the centromere repositioning to $\mathrm{Xq} 27.1 \sim 27.2$ in the $\operatorname{der}(\mathrm{X})$. In the mother of the pregnant woman, a mosaic was present of 45,X[2]/46,X,der $(\mathrm{X})($ pter $\rightarrow \mathrm{q} 27.1 \sim 27.2 \rightarrow$ neo $\rightarrow$ q27.1 27.2 $\rightarrow$ qter)[5]/46,XX[10] as shown in the 3 representative partial karyograms (C). Case 3 Immunohistochemistry together with FISH (results for the latter not shown) characterized the $\mathrm{sSMC}$ as an inv dup(acro)(pter $\rightarrow$ p13 $\rightarrow$ neo $\rightarrow$ p13 $\rightarrow$ p12::p12 $\rightarrow$ pter). Case 4 Immunohistochemistry identified a symmetric sSMC as inv dup(acro)(pter $\rightarrow$ p12 $\rightarrow$ neo::neo $\rightarrow$ p12 $\rightarrow$ pter). Case 5 The sSMC already reported in Mackie Ogilvie et al. [2001] was characterized to be neocentric as well. proven multicolor banding (aMCB) [Weise et al., 2008], it could be shown that the derivative had an identical banding pattern as the homologous normal chromosome, but the primary constriction was at the wrong place, i.e. in 18q22.1 (fig. 1, case 1, A). CENP (centromere protein) antibodies [Ewers et al., 2010] proved the pseudodicentric nature of the derivative chromosome (fig. 1, case $1, \mathrm{C})$. Therefore, the karyotype was $46, \mathrm{XY}$,der(18) (pter $\rightarrow$ q22.1 $\rightarrow$ neo $\rightarrow$ q22.1 $\rightarrow$ qter). After genetic counseling the parents decided for continuation of the pregnancy. The child was born $\sim 4$ weeks preterm and was clinically normal; however, most likely due to premature birth, the boy suffered from infant respiratory distress syndrome.

\section{Case 2}

The indication for amniocentesis was advanced maternal age. In GTG banding a derivative X chromosome was detected and suspected to have a pericentric inversion. However, as a parental chromosome analysis revealed, the pregnant woman herself had the identical derivative $\mathrm{X}$ chromosome which according to $\mathrm{aMCB}$ had no altered banding pattern (fig. 1, case 2, A). Thus, a centromere repositioning to Xq27.1 27.2 was likely. Application of CENP antibodies supported this idea (fig. 1, case 2 , B). Interestingly, the pregnant woman showed a $100 \%$ skewed X inactivation (molecular results not shown). The clinically normal mother of the pregnant woman showed the following karyotype in her peripheral blood cells: $45, \mathrm{X}[2] / 46, \mathrm{X}, \operatorname{der}(\mathrm{X})(\mathrm{pter} \rightarrow \mathrm{q} 27.1 \sim 27.2 \rightarrow$ neo $\rightarrow \mathrm{q} 27.1 \sim 27$. $2 \rightarrow$ qter)[5]/46,XX[10] (fig. 1, case 2, C). Thus, the centromere repositioning was most likely a postzygotic event in this woman who transmitted the derivative $\mathrm{X}$ chromosome to her now pregnant daughter. Unfortunately, the family was lost during follow-up.

\section{Three New Cases with sSMC}

Case 3

A 27-year-old healthy male was studied cytogenetically because of infertility. As the karyotype was $47, \mathrm{XY},+\operatorname{mar}[20]$, the detected sSMC was further characterized by multiple FISH approaches as reported in Liehr et al. [2009]. However, the sSMC was exclusively stainable by a probe for the acrocentric short arms (midi54) but not by any of the centromeric probes D13/21Z1, D14/22Z1, D15Z1 or D22Z4 (results not shown). Thus, the sSMC was described as inv dup(acro)(p10). However, application of CENP antibodies revealed the neocentric nature of the 
sSMC (fig. 1, case 3) which now is defined as inv dup(acro) (pter $\rightarrow$ p13 $\rightarrow$ neo $\rightarrow$ p13 $\rightarrow$ p12::p12 $\rightarrow$ pter).

\section{Case 4}

The clinical history of this 40 -year-old male is similar to that of case 3. Prior to intracytoplasmic sperm injection (ICSI) treatment because of his infertility, banding cytogenetics revealed a karyotype $47, \mathrm{XY},+\operatorname{mar}[25]$. As in case 3 , the sSMC was exclusively stainable by a probe for the acrocentric short arms (results not shown). Thus, the sSMC was described as inv dup(acro)(p10). After immunohistochemistry using CENP antibodies (fig. 1, case 4), the neocentric sSMC was characterized as inv $\operatorname{dup}($ acro $)($ pter $\rightarrow$ p $12 \rightarrow$ neo::neo $\rightarrow$ p12 $\rightarrow$ pter).

\section{Case 5}

The patient was born at term and did well at birth. However, at the age of 6 months he presented with delayed milestones and divergent squint. At 18 months he had a nystagmus; also his ears were diagnosed as low-set and prominent. The case was previously reported to have a karyotype 47,XY,+mar[20] and that the sSMC stains only with a reverse painting probe of itself [Mackie Ogilvie et al., 2001]. Doing immunohistochemistry with CENP antibodies (fig. 1, case 4), it turned out to be a neocentric sSMC as well.

\section{Comparison with Ancestral Centromeres}

Previous studies suggested a possible relation of neocentromeres in clinical cases and so-called ancestral centromeres, i.e. some neocentromeres localized to chromosomal domains where ancestral centromeres were inactivated during evolution (e.g. 15q25 and 6p22.1) [Ventura et al., 2003; Capozzi et al., 2009]. Also, there are examples of centromeres and evolutionary new centromeres sharing the same seeding point domain (e.g. 3q24, 9q33.1, and 13q21) [Ventura et al., 2004; Cardone et al., 2006; Capozzi et al., 2008]. Such a potential correlation of the neocentromere at $18 \mathrm{q} 22.1$ in case 1 and the evolutionary new centromere in macaque chromosome 18, at 18q21.2 [Carbone et al., 2009], was tested using appropriate BAC clones (fig. 1, case 1, B), but no co-localization was found. For the other newly observed neocentromeres of this study, no corresponding ancestral or evolutionary new centromeres are known.

\section{Conclusion}

Overall, here we report 5 more cases with neocentric derivative chromosomes. Two of these cases had a centromere repositioning and both of them are the first reported neocentromeres in subbands 18q22.1 and Xq27.1 27.2. Interestingly, in both cases it was initially suggested that an inversion could be the reason for the aberrant banding pattern of the derivative chromosomes. Thus, such neocentric cases with centromere repositioning might be easily overlooked and may be more frequent than suggested at present. Furthermore, all now 9 reported cases with centromere repositioning were clinically normal. This could be a hint that genes in neocentromeric regions are expressed normally, irrespective of neocentric constriction, as previously shown for one case [Voullaire et al., 1993].

\section{Acknowledgments}

Supported in parts by DAAD (D07/00070) and grant 2011_ A42 from the Else Kröner-Fresenius-Stiftung.

\section{References}

Capozzi O, Purgato S, Verdun di Cantogno L, Grosso E, Ciccone R, et al: Evolutionary and clinical neocentromeres: two faces of the same coin? Chromosoma 117:339-344 (2008).

Capozzi O, Purgato S, D’Addabbo P, Archidiacono N, Battaglia P, et al: Evolutionary descent of a human chromosome 6 neocentromere: a jump back to 17 million years ago. Genome Res 19:778-784 (2009).
Carbone L, D'Addabbo P, Cardone MF, Teti MG, Misceo D, et al: A satellite-like sequence, representing a 'clone gap' in the human genome, was likely involved in the seeding of a novel centromere in macaque. Chromosoma 118: 269-277 (2009).

Cardone MF, Alonso A, Pazienza M, Ventura M, Montemurro G, et al: Independent centromere formation in a capricious, gene-free domain of chromosome 13q21 in Old World monkeys and pigs. Genome Biol 7:R91 (2006).
Ewers E, Yoda K, Hamid AB, Weise A, Manvelyan $\mathrm{M}$, Liehr T. Centromere activity in dicentric small supernumerary marker chromosomes. Chromosome Res 18:555-562 (2010).

Liehr T: Small supernumerary marker chromosomes (sSMC). http://www.fish.uniklinikum-jena.de/sSMC.html (accessed on December 12, 2011). 
Liehr T, Ewers E, Kosyakova N, Klaschka V, Rietz F, et al: Handling small supernumerary marker chromosomes in prenatal diagnostics. Expert Rev Mol Diag 9:317-324 (2009).

Liehr T, Kosyakova N, Weise A, Ziegler M, Raabe-Meyer G: First case of a neocentromere formation in an otherwise normal chromosome 7. Cytogenet Genome Res 218: 189-191 (2010).
Mackie Ogilvie C, Harrison RH, Horsley SW, Hodgson SV, Kearney L: A mitotically stable marker chromosome negative for whole chromosome libraries, centromere probes and chromosome specific telomere regions: a novel class of supernumerary marker chromosome? Cytogenet Cell Genet 92:69-73 (2001).

Ventura M, Mudge JM, Palumbo V, Burn S, Blennow E, et al: Neocentromeres in 15q24-26 map to duplicons which flanked an ancestral centromere in 15q25. Genome Res 13: 20592068 (2003).

Ventura M, Weigl S, Carbone L, Cardone MF, Misceo D, et al: Recurrent sites for new centromere seeding. Genome Res 14:1696-1703 (2004).
Voullaire LE, Slater HR, Petrovic V, Choo KH: A functional marker centromere with no detectable alpha-satellite, satellite III, or CENP-B protein: activation of a latent centromere? Am J Hum Genet 52:1153-1163 (1993).

Weise A, Mrasek K, Fickelscher I, Claussen U, Cheung SW, et al: Molecular definition of high-resolution multicolor banding probes: first within the human DNA sequence anchored FISH banding probe set. J Histochem Cytochem 56:487-493 (2008) 